\title{
Student Participation and Interaction in Online Case-Based Discussions: Comparing Expert and Novice Facilitation
}

\author{
Yishi Long \\ Adrie A. Koehler \\ Purdue University, USA
}

\begin{abstract}
Discussion is an essential component in case-based learning (CBL), as it offers students the opportunity to consider diverse perspectives, clarify confusion, and construct understanding. As a facilitator bears most of the responsibility for the overall success of CBL, understanding how facilitation strategies influence interactions during discussions is worthwhile. However, previous CBL facilitation research has primarily considered student perspectives during case discussions, without examining relationships between facilitator experience and student interaction and participation. This study combined social network analysis and content analysis to compare the structure of expert and novice instructors' discussion posts and to consider their relationship to student participation and interaction in online case discussions. Results showed that both the expert and novice instructors used facilitation strategies involving social congruence, cognitive congruence, and content expertise frequently in the discussions; however, when and how they used a combination of these strategies was noticeably different. These differences influenced student interaction. More specifically, students tended to interact with others more actively and densely as a result of questions initiated by the expert facilitator. Suggestions are provided for novice facilitators.
\end{abstract}

Keywords: instructor facilitation, student participation and interaction, case-based discussions, social network analysis

Long, Y., \& Koehler, A. A. (2021). Student participation and interaction in online case-based discussions: Comparing expert and novice facilitation. Online Learning, 25(4), 220-246.

DOI: $10.24059 /$ olj.v25i4.2901 
Case-based learning (CBL) is widely used to prepare instructional design (ID) learners to develop problem-solving and decision-making skills (Ertmer \& Koehler, 2014, 2015, 2018; Koehler et al., 2019). It situates learning in authentic, complex contexts and prompts students to identify case problems and propose solutions (Ertmer \& Koehler, 2014). Students commonly struggle with case problems because they are ill-structured, include ambiguous details, and have multiple potential solutions (Jonassen, 2011). Therefore, discussions are considered an important part of CBL, as they offer learners a place to collaboratively make sense of the complexities involved with cases and promote students' problem solving and higher-order thinking (Ertmer \& Koehler, 2014; Ertmer \& Stepich, 2002; Yew \& Schmidt, 2012). Through case discussions, students work with peers and their instructor to share perspectives, offer suggestions, and engage cognitively in developing deeper understandings of case problems and solutions (Ertmer \& Koehler, 2018).

To gain the most from case discussions, instructors must embrace a facilitator role, guiding students through the problem-solving process and sharing the direction of the learning process with students, who are responsible for co-constructing their understanding (Ertmer \& Koehler, 2015; Hmelo-Silver, 2004). Therefore, instructor facilitation is essential in creating well-functioning case discussions and supporting students' efforts to solve different kinds of problems (Hemlo-Silver \& Barrows, 2006; Rico \& Ertmer, 2015; Yew \& Yong, 2014). Although research has established the importance of instructor facilitation in generating and maintaining student interaction during case discussions, little consideration has been given to how discussion outcomes differ across expert and novice instructors. In this study, we used social network analysis (SNA) to identify the discussion structures and interaction among the instructors and students (Yang et al., 2017) and content analysis (Hara et al., 2000) to investigate and compare expert and novice instructors' facilitation methods (De Laat et al., 2007). By using these methods, we are able to compare differences in student interaction and participation in case discussions resulting from the efforts of a novice and an expert facilitator and offer insight into how specific facilitation strategies can be used to improve case discussions.

\section{Case-based Learning}

\section{Literature Review}

As a student-centered pedagogical approach, $\mathrm{CBL}$ is consistent with constructivist learning principles, using real-world problems to foster students' deep analysis and problem solving (Ertmer \& Koehler, 2014). In problem-centered approaches, like CBL, students analyze complex problems with multiple potential solutions, and gain knowledge that is transferable to future situations (Hmelo-Silver, 2004). Finally, ill-structured case problems simulate real-world situations offering learners an opportunity to develop professional skills (e.g., problem solving) in a safe and engaging way (Tawfik \& Jonassen, 2013).

Generally, problem-solving has been described as a process comprising two main steps: problem finding and solution generation (Hmelo-Silver, 2004). However, developing problemsolving skills is difficult for learners, and five challenges students commonly face during problem-centered learning experiences include: limited domain knowledge and disconnection between prior knowledge and case scenarios; high cognitive load when synthesizing relevant information; lack of extensive analysis of problem representation; an inaccurate judgment of a solution plan; and low intrinsic motivation (Law et al., 2020). To combat these difficulties during CBL experiences, discussions offer learners a place to support the conceptualization of problems 
and development of solutions when considering authentic and ill-defined problems (Ertmer et al., 2017; Goeze et al., 2014; Rico \& Ertmer, 2015). Specifically, online discussion in CBL engages students in the development of active knowledge construction, enhances student performance in analytical and problem-solving skills, and prompts students' coverage of an afforded problem space (Ertmer \& Koehler, 2014, 2015). To prepare for and maximize the benefits of discussions, students are often required to read and analyze a case by individually completing a case analysis beforehand (Ertmer et al., 2017).

According to Rico and Ertmer (2015), an instructor must assume a facilitator's role in online case discussions to support students' knowledge construction and co-construction in problem solving. (Note: Given the expectation that an instructor in problem-centered instruction is a facilitator of student learning, we use the words "instructor" and "facilitator" interchangeably.) Facilitation of online discussions include structuring the initial discussion prompt to address the problem space (Ertmer \& Koehler, 2015); probing students' investigations and interaction (Ertmer \& Koehler, 2014); and bringing closure to the case discussion (Rico \& Ertmer, 2015).

\section{Instructor Facilitation}

Although meaningful ill-structured problems have the potential to engage learners and prompt collaboration, they do not guarantee effective discussions will ensue (Hmelo-Silver, 2004). The facilitator must scaffold the discussion by supporting students' conceptual understanding, moving students from problem identification to solution generation, and promoting students' willingness to participate and interact actively (Ertmer \& Koehler, 2014). In the absence of a dedicated facilitator, students tend to discuss case issues at a surface level, miss key case aspects, and focus on generating solutions without fully understanding problems (Ertmer \& Koehler, 2015). In short, "the core of case teaching - and most of the art of it-lies in managing the students' discussion" (Andersen \& Schiano, 2014, p. 66). With the nature of case problems as their focus, Schmidt and Moust (1995) proposed a framework characterized an effective facilitator as using strategies in three major areas: use of expertise (possessing relevant content knowledge), social congruence (interacting with students informally and showing an attitude of caring), and cognitive congruence (presenting content in an understandable manner).

Previous research supports the need for facilitators to be content experts, demonstrating a relationship between a facilitator's subject-matter experience and student academic performance and satisfaction (Schmidt, 1994; Schmidt et al., 1993). Facilitators with relevant domain knowledge can more readily use their expertise to meaningfully scaffold learners with limited experience and to address misconceptions (Schmidt, 1994). In online case discussions, content expertise is associated with prompting students to think deeply, clarifying content and providing examples, asking students for clarification, and emphasizing the focus of the content being discussed (Ertmer \& Koehler, 2015).

In addition, research underscores the significance of facilitators' social congruence in actively engaging students and establishing a non-threatening learning environment, which can lead to a deeper understanding of students' feelings and difficulties and offer more effective guidance (Chng et al., 2011; Kassab et al., 2006; Schmidt \& Moust, 1995). Chng et al. (2011) suggested that students showed more positive learning attitudes when interacting with a more socially congruent facilitator. Specifically, social congruent instructors implement affective (e.g., disclosing information from their background), cohesive (e.g., addressing student posts by name), and interactive (e.g., inviting all students to respond) strategies when facilitating online discussions (Watson et al., 2018). 
Finally, cognitive congruence is an important attribute of effective problem-centered instructors (Yew \& Yong, 2014). Cognitive congruence refers to facilitators' ability to present content and explain things in easily understood ways (Shmidt \& Moust, 1995). Previous research suggests that student instructors, as compared to faculty instructors, were more cognitively congruent because they better understood problems facing students and proposed more easily understood probing questions when responding to peers (Dolmans et al., 2002; Schmidt et al, 1994). In online discussions, cognitive congruence methods include emphasizing relevant ideas, directing students' attention, and providing a summary of key ideas being discussed (Watson et al., 2018).

During facilitation of problem-centered environments, using a combination of social congruence, content expertise, and cognitive congruence facilitation strategies is important (Watson et al., 2018; Yew \& Yong, 2014). While these skills are essential, novice instructors may have challenges utilizing strategies to effectively guide and support students. For instance, they may be inflexible and tend to stay close to their lesson plans, limiting students' opportunities to be exposed to other ideas (Berliner, 2001). Additionally, some research suggests that the frequency of instructor interaction in online discussions has no significant impact on students' progress and achievement (see Hoey, 2017). Therefore, facilitators in problem-centered environments need to "identify who needs support, what kind of support, when to provide support, and how to provide support" (Law et al., 2020, p. 333).

\section{The Use of Social Network Analysis to Explore Participation and Interaction}

While effective facilitation is established as an important element of a meaningful online CBL experience, determining the impact of facilitation can be challenging. As an emerging approach, SNA offers a way to gain insight into the interactions taking place during CBL. According to Breiger (2004), SNA is "the disciplined inquiry into the patterning of relations among social actors, as well as the patterning of relationships among actors at different levels of analysis (such as persons and groups)" (p. 507). It is commonly used to analyze a human network structure and the positions (e.g., active, peripheral, outsider) of people within the network (Carolan, 2014).

In online learning, SNA has served as an effective method to understand the structure of a network and the position of participants within the network, identify and analyze interaction patterns, and improve learning community design (Cela et al., 2015). A social network has two fundamental elements: nodes (participants) and edges (connections across these nodes) (Yang et al., 2017). For instance, in an online discussion, the nodes are students and instructors, and the edges, which may be directional, are connections between the individuals in the discussion network. SNA can measure how much individuals engage in the discussions at a network-level and node-level. At the network-level, density is the number of edges in a network divided by the total possible number of edges, which is used to describe how connected a network is (Carolan, 2014). At the node-level, several centrality measures can be made, with the most commonly used indicators being degree centrality, betweenness centrality, and closeness centrality (Yang et al., 2017).

De Laat et al. (2007) used density and degree centrality metrics to study the dynamics of participants' interaction and how well they connected in the discussions. Findings showed that students with a high value of degree centrality are active, and students with the highest value of degree centrality are central participants in the discussions. Erlin et al. (2009) applied the betweenness and closeness centrality metrics to an online discussion to monitor and evaluate 12 
graduate students' participation. They found that students with high values of betweenness and closeness centrality quickly interact with others and tend to receive information flowing through the network quickly. In considering the relationship between instructor involvement and student interaction in online discussions, Doran et al. (2011) suggested tracking instructors' betweenness and centrality measures across different forums to see if student interaction changes accordingly. They indicated that intensive instructor involvement may decrease student involvement and vice versa.

\section{Purpose}

While the importance of instructor facilitation in problem-centered discussions has been established (Ertmer \& Koehler, 2015; Schmidt \& Moust, 1995; Yew \& Yong, 2014), little is known regarding the differences in expert and novice discussion posts and how these differences influence student participation and interaction in case discussions. Specifically, we used SNA to examine student participation and interaction in relation to instructor facilitation level (expert vs. novice) across multiple case discussions, and then, we analyzed instructor discussion posts based on social congruence, cognitive congruence, and content expertise (Watson et al., 2018; Schmidt \& Moust, 1995; Yew \& Yong, 2014) to aid the understanding of student interactions. The following questions guided our research:

1. How does differing facilitation between an expert and novice instructor relate to student participation and interaction in online case discussions?

2. What are the differences in the structures of discussion posts between an expert and novice instructor in online case discussions?

\section{Methods}

\section{Research Design}

Although SNA provides an effective way for examining the interactions taking place in an online discussion and relationships among participants, this approach does not provide insight into the reason these interactions and relationships are forming. To understand the relationship between instructor facilitation efforts in an online case discussion and learners' participation and interaction, SNA alone was not sufficient. Therefore, we used a mixed-method social network analysis (MMSNA) (Froehlich et al., 2020) to triangulate quantitative SNA data with content analysis to gain a rich and deep understanding of the differences between expert and novice instructor facilitation styles and their influence on student participation and interaction in case discussions. The definition of MMSNA associates mixed methods, combining quantitative and qualitative research components (Johnson et al., 2007) and focusing on collecting, analyzing, and integrating quantitative and qualitative data in a study to enhance the breadth and depth of understanding (Froehlich et al., 2020). Quantitative data, in the form of the number of students' and instructors' discussion posts, were used to map the discussion structures and demonstrate interaction among the instructors and students. Qualitative data (instructors' discussion posts and case discussion summaries) were analyzed to deepen understanding of discussion structures and compare the differences between expert and novice instructors' facilitation methods and their impact on student interactions.

\section{Research Context}

Data were collected from an online graduate-level core course (Advanced Practices in Learning Systems Design) at a large Midwestern university during fall 2018. The course was designed to assist students in developing instructional design (ID) skills using a case-based approach. As ID represents a typically collaborative activity, a key aspect of the course included 
asynchronous discussions to prompt interaction and draw out learners' varying expertise and backgrounds.

During the eight-week course, learners completed three instructor-facilitated case discussions. Prior to these discussions, students submitted a case analysis assignment individually (due by Monday morning) to describe key stakeholders, identify and prioritize case challenges and limitations, and create and evaluate proposed solutions prior to participating. Case assignments were designed to prepare them to participate in the upcoming discussions. Discussions opened Monday morning and ran through Saturday afternoon. When each discussion concluded, instructors returned individual feedback on case analyses. Discussion prompts focused attention on key design challenges and constraints in the first half of the week. In the second half of the week, students were prompted to discuss solutions that addressed previously identified design challenges. Both instructors facilitated the same discussion among the same students and provided comments that were viewable by everyone to encourage interaction. Additionally, while instructors had regular meetings to discuss course facilitation efforts, specific frequencies of posts were not set. At the end of each week, one instructor provided a case discussion summary to all students. To receive full discussion points, besides the initial posts, each student was required to create 4 to 5 substantive responses, well distributed throughout the week.

\section{Participants}

Participants included an expert CBL instructor, a novice CBL instructor, and 12 graduate students enrolled in the course (2 male, 10 female; 10 M.S. students, 2 Ph.D. students). As this was an advanced course in the online program, at a minimum, learners had completed five courses prior to this course, all requiring participation in online discussions. Moreover, ten students had previously worked or were working in $\mathrm{K}-12$ and higher education, while the other two had professional experience in IT industries. Seven students had participated in CBL in previous work, while five individuals had no experience with CBL. The expert instructor had more than ten years of online teaching experience in higher education and nine years of experience using a case-based method in both face-to-face and online settings. Specifically, she had facilitated an online version of the course four times and previously implemented other case learning experiences as a high school teacher and an undergraduate instructor. The novice instructor had previously completed the course in a face-to-face format but had never taught online or facilitated case discussions. Previously, she was a teaching assistant for an undergraduate educational technology course that used CBL, but she was not responsible for facilitating discussions.

\section{Data Collection}

Across the three instructor-facilitated case discussions (IF1, IF2, and IF3), we collected posts made by the students $(n=442)$, the expert instructor $(n=41)$, and the novice instructor $(n$ = 35) from Blackboard Learn. Out of the 518 total posts in the forums, IF1 had 150 posts, IF2 had 161 posts, and IF3 had 207 posts. The expert instructor's posts comprised 7.9\%, the novice instructor's posts comprised 6.8\%, and the students' posts comprised $85.3 \%$ of the overall discussion. We also collected two case discussion summaries the expert CBL instructor provided for IF1 and IF2 and one case discussion summary the novice CBL instructor provided for IF3. The three instructor discussion summaries were excluded from the interaction matrix because they were posted at the end of the discussion to bring closure to the conversation, with no expectation of generating additional posts from students. 
All participant identities were removed prior to analysis to protect confidentiality. Students were labeled as S1 to S12. The expert instructor was labeled T1, and the novice instructor was labeled T2.

\section{Data Analysis}

To prepare the data for SNA, we created an interaction matrix among the participants, and to consider interactions among participants, we connected a discussion reply to the previous post when a participant's or several participants' names were mentioned. For example, if one discussion post mentioned several participants' names, we viewed this post as one message that went to several participants and attributed to the frequency of different receivers. If a reply did not include a specific receiver's name, we labeled it as a response to the individual post hierarchically above the reply to avoid losing connections among the participants. Students' initial posts to respond to the expert instructor's discussion prompts in each discussion were excluded in the interaction matrix because they did not capture interaction among participants. Instead, these initial discussion posts were viewed as a participation requirement for everyone, rather than how they chose to interact with others.

Second, we examined student participation and interaction and instructor facilitation quantitatively using an open-source network exploration and manipulation software called Gephi (Bastian et al., 2009). We used Gephi to calculate centrality values at each participant's interaction level (see Table 1), the density of the three case discussions, and to map the visualization of each discussion network (see Figure 1).

Finally, we applied a deductive approach to analyze and code the instructors' discussion prompts, facilitation posts, and discussion summaries to further explain quantitative analysis results. Specifically, we used an established coding scheme for examining instructors' efforts in online settings (Richardson et al., 2015). This scheme has been adapted and applied in online CBL research to provide a comprehensive consideration of meaningful facilitation (Watson et al., 2018), as aligned with an established framework capturing areas of effective facilitation (i.e., social congruence, cognitive congruence, and content expertise [Schmidt \& Moust, 1995]). For example, we identified that both instructors applied the use of social congruence (e.g., acknowledging student ideas, addressing student posts by mentioning their names), cognitive congruence (e.g., clarifying ideas, emphasizing and stressing important ideas, directing student attention), and content expertise (e.g., using direct question after reviewing student responses) (see Table 2). Typically, a single instructor post included multiple strategies (see Table 3). We also totaled the frequencies for each code for the two instructors to capture potential differences across the structure of instructor posts (see Appendix A).

\section{Validity and Reliability}

We collected the data through three sources (i.e., instructor posts, instructor interaction frequencies, and student participation and interaction frequencies), and analyzed the data using two techniques (SNA and content analysis) to strengthen validity and reliability. Moreover, we utilized relevant studies as a foundation to enhance internal reliability. For instance, we used a widely known coding scheme to investigate effective CBL facilitation. Lastly, we coded case discussions and the instructors' discussion summaries independently and discussed divergent interpretations to reach consensus (Creswell, 2014).

\section{Measures of Network and Participant Level Interaction}

Network Density. The ratio of the actual edges in a network to the total possible edges was used to show how students were connected in each instructor-facilitated discussion. The value of density varies between 0 and $100 \%$. We used the density metric to show how dense each 
case discussion was. The more participants connected to one another in the discussion, the higher the density value is.

Degree Centrality. The degree centrality is the total connections a participant had in the discussion. We used it to uncover the most connected participants, indicating the participants who received from and sent out the largest number of messages to others in the discussion. In-degree Centrality. The in-degree centrality is the number of replies a participant received from other participants in the discussion. Receiving the highest number of messages could be regarded as a sign of popularity or prestige.

Out-degree Centrality. The out-degree centrality is the number of replies a participant sent out to others. Participants who sent out the largest number of messages were identified as influential participants because they made others aware of their perspectives.

Betweenness Centrality. The betweenness centrality is the number of times a participant lay on the path connecting all other participants. A participant with the highest betweenness centrality indicates that he or she had the most control over the discussion because the information would need to pass through him or her. We used the betweenness centrality to uncover who served as a bridge to influence the flow of the discussions.

Closeness Centrality. The closeness centrality is a measure of the distance between each participant and others in the discussion. Participants with high closeness centrality value means that their messages could go quickly to all other participants. We used the closeness centrality to find which participants were most reachable to participants than any other participants.

\section{Results}

\section{Frequency of Instructor Facilitation and Student Participation and Interaction}

To show the overall connections among the participants in the three instructor-facilitated case discussions (IF1, IF2, and IF3), we calculated the density values. Results show that the discussion density from IF1 to IF3 were $35.7 \%, 48.4 \%$, and $53.8 \%$, respectively, indicating a gradual increase from IF1 to IF3, and the overall interaction levels peaked during IF3.

To explore how the two instructors interacted with the students in each discussion, we started by determining the centrality values for each participant and presenting the visual representation of the discussion (see Figure 1). As illustrated in Table 1, centrality measures provided a way to consider participant interactions across the three discussions by capturing the number of connections per participant (degree centrality), the number of replies received (indegree centrality), the number of responses to others' posts (out-degree centrality), the influence a participant had on the discussions (betweenness centrality), and the reach of a participant's message (closeness centrality). In IF1, in-degree and out-degree centrality measures indicated that both instructors were active facilitators to make sure students were interacting with others. However, neither instructor was the most central or influential participant. Instead, students S7 and S12 had the highest in-degree centrality values of 9, indicating that they were in the prominent positions in the discussion. Students S7 and S8 had the highest out-degree centrality values of 8 , suggesting that they were the most influential in making others aware of their opinions in the discussion. On the other hand, students S1 and S10 had the lowest out-degree centrality values, indicating that they contributed minimally. The betweenness and closeness scores for the expert instructor T1 and novice instructor T2 were above the mean and median scores for the students, thereby indicating that the instructors played an essential role in connecting different students and transmitting information quickly. Specifically, the novice 
instructor T2 had the highest betweenness centrality value, indicating that she was the gatekeeper and could control the communication flows.

In IFI visualization, all students were involved to some extent, and the participants formed two dense subgroups. Participants in each group were more closely connected among each other than to others in another group. Each instructor was in one group to communicate with students. Visibly, instructor T1 formed a dense group to facilitate interaction with students S2, S3, S6, S7, S11, and S12, while instructor T2 prompted relative sparse connections among students S1, S4, S5, S8, S9, and S10. Students S1, S5, S9, and S10 were positioned away from the center of the discussion and were all in the novice instructor T2's group. Based on the visualization, the novice instructor T2 failed to engage less-active students (e.g., students S1, S5, S9, and S10) to participate more in the discussion.

Beginning in IF2, the number of general interactions increased. The most substantial contributors were students, such as students S4 and S11 who had the highest number of outdegree centrality values of 9. Moreover, student S9's interaction levels improved dramatically in IF2, which was evidenced by her degree centrality values. The expert instructor T1 maintained a balance between in and out degree centrality with a score of 8 , with high values of betweenness centrality value of 8.25 and closeness centrality score of 0.75 to prompt the whole discussion forward. The novice instructor T2 had an out-degree centrality value of 7 and an in-degree centrality metric of 4 , suggesting that she was a less prominent facilitator to interact with in the discussion. Her betweenness centrality value dropped vastly from 35.71 in IF1 to 4.2 in IF2, indicating that she moved away from the center in connecting students. Rather, student S7 had an in-degree centrality value of 11 and held the highest betweenness centrality value of 11.84 , suggesting that she was the broker, bridging unconnected students in the discussion. 
Expert and Novice Facilitation in Online Discussions

Table 1

Centrality Measures of Instructors and Students across the Three Case Discussions

\begin{tabular}{|c|c|c|c|c|c|c|}
\hline & Participant & Degree & In-degree & Out-degree & Betweenness & Closeness \\
\hline \multirow{14}{*}{ IF1 } & T1 & 15.00 & 7.00 & 8.00 & 10.94 & 0.71 \\
\hline & $\mathrm{T} 2$ & 13.00 & 7.00 & 6.00 & 35.71 & 0.67 \\
\hline & S1 & 1.00 & 0.00 & 1.00 & 0.00 & 0.42 \\
\hline & S2 & 6.00 & 3.00 & 3.00 & 0.00 & 0.48 \\
\hline & S3 & 7.00 & 3.00 & 4.00 & 0.25 & 0.50 \\
\hline & S4 & 10.00 & 5.00 & 5.00 & 8.76 & 0.60 \\
\hline & S5 & 6.00 & 2.00 & 4.00 & 12.64 & 0.55 \\
\hline & S6 & 9.00 & 5.00 & 4.00 & 1.80 & 0.55 \\
\hline & S7 & 17.00 & 9.00 & 8.00 & 17.87 & 0.71 \\
\hline & S8 & 15.00 & 7.00 & 8.00 & 22.98 & 0.75 \\
\hline & S9 & 3.00 & 1.00 & 2.00 & 1.03 & 0.52 \\
\hline & $\mathrm{S} 10$ & 4.00 & 3.00 & 1.00 & 0.00 & 0.41 \\
\hline & S11 & 8.00 & 4.00 & 4.00 & 0.20 & 0.55 \\
\hline & S12 & 16.00 & 9.00 & 7.00 & 22.81 & 0.67 \\
\hline \multirow{14}{*}{ IF2 } & T1 & 16.00 & 8.00 & 8.00 & 8.25 & 0.75 \\
\hline & $\mathrm{T} 2$ & 11.00 & 4.00 & 7.00 & 4.20 & 0.71 \\
\hline & S1 & 0.00 & 0.00 & 0.00 & 0.00 & 0.00 \\
\hline & S2 & 15.00 & 9.00 & 6.00 & 4.75 & 0.67 \\
\hline & S3 & 14.00 & 7.00 & 7.00 & 3.94 & 0.71 \\
\hline & S4 & 17.00 & 8.00 & 9.00 & 7.65 & 0.80 \\
\hline & S5 & 11.00 & 7.00 & 4.00 & 3.42 & 0.57 \\
\hline & S6 & 10.00 & 5.00 & 5.00 & 3.12 & 0.63 \\
\hline & S7 & 19.00 & 11.00 & 8.00 & 11.84 & 0.75 \\
\hline & S8 & 14.00 & 7.00 & 7.00 & 1.94 & 0.71 \\
\hline & S9 & 10.00 & 4.00 & 6.00 & 3.90 & 0.67 \\
\hline & $\mathrm{S} 10$ & 11.00 & 5.00 & 6.00 & 2.47 & 0.67 \\
\hline & S11 & 18.00 & 9.00 & 9.00 & 9.77 & 0.80 \\
\hline & $\mathrm{S} 12$ & 10.00 & 4.00 & 6.00 & 3.76 & 0.67 \\
\hline \multirow{14}{*}{ IF3 } & T1 & 13.00 & 6.00 & 7.00 & 4.55 & 0.68 \\
\hline & $\mathrm{T} 2$ & 19.00 & 9.00 & 10.00 & 7.43 & 0.76 \\
\hline & S1 & 1.00 & 1.00 & 0.00 & 0.00 & 0.00 \\
\hline & S2 & 13.00 & 8.00 & 5.00 & 4.91 & 0.62 \\
\hline & S3 & 13.00 & 5.00 & 8.00 & 4.56 & 0.72 \\
\hline & S4 & 18.00 & 9.00 & 9.00 & 5.34 & 0.72 \\
\hline & S5 & 11.00 & 5.00 & 6.00 & 14.41 & 0.65 \\
\hline & S6 & 14.00 & 7.00 & 7.00 & 4.70 & 0.68 \\
\hline & S7 & 20.00 & 10.00 & 10.00 & 14.41 & 0.81 \\
\hline & S8 & 16.00 & 8.00 & 8.00 & 2.69 & 0.68 \\
\hline & S9 & 10.00 & 5.00 & 5.00 & 0.72 & 0.59 \\
\hline & S10 & 13.00 & 7.00 & 6.00 & 0.74 & 0.62 \\
\hline & S11 & 18.00 & 9.00 & 9.00 & 5.84 & 0.72 \\
\hline & S12 & 17.00 & 9.00 & 8.00 & 7.71 & 0.68 \\
\hline
\end{tabular}




\section{Figure 1}

Visualization of participant interaction across the three case discussions

IF1

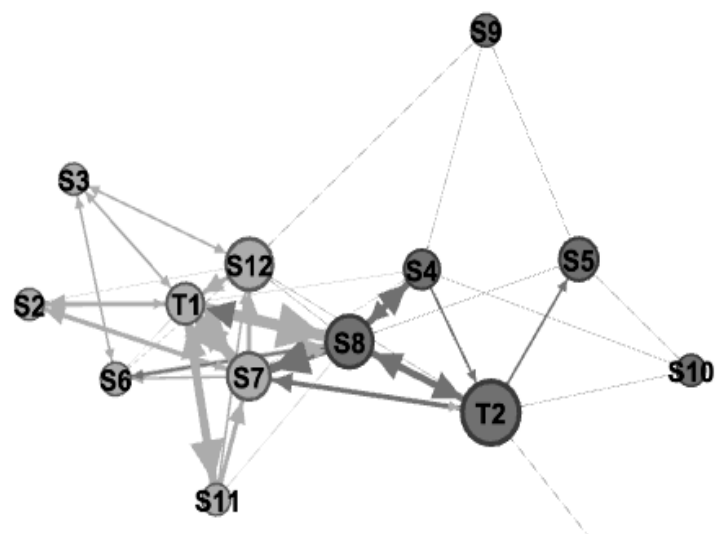

(1)

IF3

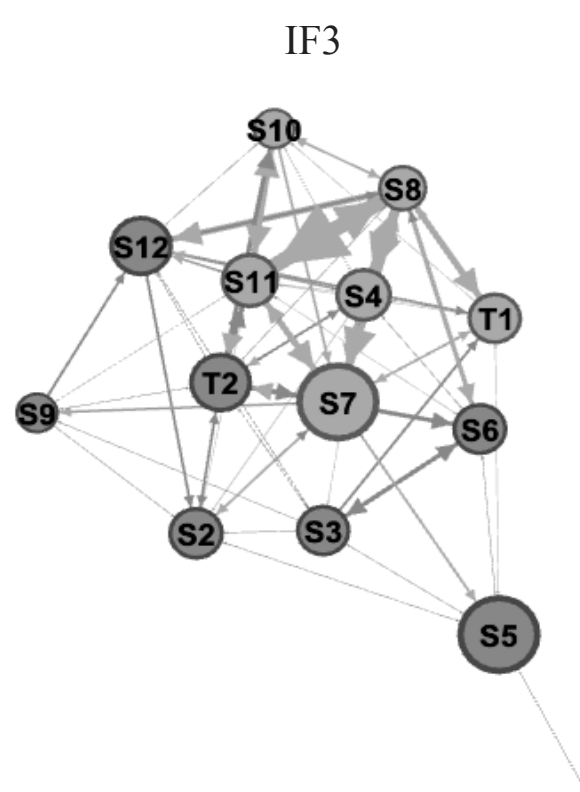

(51

Note. The node color is associated with the subgroup, and the edges are represented in the corresponding colors. An arrow showed each edge from the sender to the receiver. The node size is associated with betweenness centrality values. The more interaction between the nodes, the thicker the edge is.
IF2

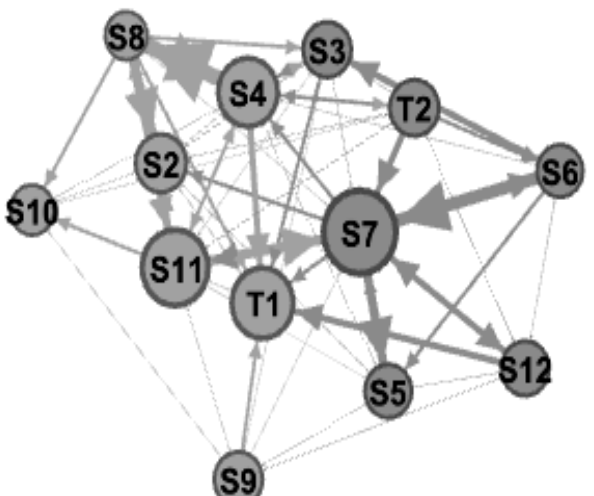

(s9) 
As illustrated in Figure 1, two connected subgroups were formed in IF2, and each instructor was in one of the groups. Student S1 did not participate in this discussion, thus having no interaction with others and not showing in the visualization. In the expert instructor T1's group, she found marginal students S9 and S10 of IF1 and interacted with them. The novice instructor T2 had a more densely connected group than IF1, but she lost the central position in connecting students. The number of students she connected with decreased from nine in IF1 to five in IF2. Since her responsiveness decreased, student S7 tended to be highly connected with others.

As the course progressed, IF3 showed the highest level of interaction. Both instructors continued interacting with students to move the discussion forward, which was represented by their above-mean betweenness centrality scores. However, neither of them coordinated interaction among all the participants. Student S7 had the highest betweenness and closeness centrality values of 14.41 and 0.81 , respectively, indicating that she could influence the flow around IF3 and quickly make her posts reach others.

Two connected groups were formed in IF3, and each instructor was in a group. As Figure 1 displays, the expert instructor T1 formed a dense group to facilitate interaction with students S4, S7, S8, S10, and S11, while the novice instructor T2 facilitated relative sparse connections among students S1, S2, S3, S5, S6, S9, and S12. There were no isolated students during IF3 because all participants had at least one direct communication with another participant. However, student S1 was extremely peripheral, not contributing to the discussion productivity. She received one comment from student $\mathrm{S} 5$, but she did not respond.

Across the case discussions, both instructors maintained their role as facilitators, but they did not play the central role of information diffusion after helping students become comfortable with case discussions at the beginning of the course. This facilitation method helped improve interaction among students. As the instructors took a step back in discussions, some students, for example, student S7, started to embrace the key facilitator role in IF2 and IF3.

\section{Structures of Instructor Facilitation Artifacts}

To have a clear understanding of how the two instructors facilitated the three discussions and interacted with students, we examined instructor posts in the three discussions separately. The expert instructor T1 made 41 posts and the novice instructor T2 made 35 posts. More specifically, analysis of instructor T1's discussion posts resulted in a total of 176 indicators (Social Congruence $=109,61.9 \% ;$ Cognitive Congruence $=29,16.5 \%$; Content Expertise $=38$, $21.6 \%$ ); and analysis of instructor T2's discussion posts resulted in a total of 192 indicators (Social Congruence $=127,66.2 \%$; Cognitive Congruence $=39,20.3 \%$; and Content Expertise $=$ $26,13.5 \%)$.

Across the three discussions, instructor T1 demonstrated more expertise, but she used less social and cognitive congruent strategies than instructor T2. The totaled frequencies for each code of the two instructors revealed the top 10 facilitation strategies used by them. Seven methods appeared to be the same: (1) acknowledging student ideas, (2) addressing student posts by mentioning their name, (3) showing enthusiasm about student discussion posts, (4) using direct questions after reviewing student responses, (5) directing student attention, (6) clarifying ideas, and (7) greeting students. Four of these strategies related to social congruence, two related to cognitive congruence, and one related to content expertise. For the other three most observed facilitation strategies, instructor T1 used two related to content expertise (tempering instructor expertise to promote a non-authoritative environment and prompting and structuring the direction of the discussion) and one pertaining to social congruence (inviting students to join and 
contribute to the discussion). Instructor T2 commonly used two social congruence strategies (encouraging students and using emotions to indicate feelings) and one cognitive congruence strategy (emphasizing and stressing important ideas). That is, for the three different strategies, instructor T1 applied content expertise and social congruence strategies to deepen students' learning in a non-threatening environment. Instructor T2 used social congruence and cognitive congruence strategies to encourage and support students to emphasize relevant ideas shared (see Table 2 for the top 10 strategies used by each instructor).

When making a post, the expert instructor T1 more frequently invited all students to continue the discussion to stimulate interaction than the novice instructor T2. In total, instructor $\mathrm{T} 1$ invited students to join the ongoing conversation ten times, while instructor T2 only invited students three times. Moreover, both instructors used a combination of facilitation strategies for most posts, but their combined methods differed. Specifically, the most observed facilitation strategies that instructor T1 used were a combination of social congruence, cognitive congruence, and content expertise $(n=11)$, and a combination of social congruence and content expertise $(\mathrm{n}=11)$. Instructor $\mathrm{T} 2$ also used a combination of social congruence, cognitive congruence, and content expertise frequently $(\mathrm{n}=12)$, and the second most observed facilitation strategies she used were a combination of social congruence and cognitive congruence $(n=9)$. For instructor T1, she did not include social congruence strategies for the six prompts that she used to provide direction for the discussion. Instructor T2 had one post that was entirely focused on cognitive congruence and content expertise (see Table 3 for typical posts for each instructor).

After each discussion, one of the instructors provided final thoughts to summarize the case discussions and emphasized important and missed case aspects. The expert instructor T1 made a summary for IF1 and IF2. IF1 summary had 31 indicators (Social Congruence = 13, Cognitive Congruence $=14$, Content Expertise $=4$ ), and IF2 summary had 20 indicators (Social Congruence $=7$, Cognitive Congruence $=14$, Content Expertise $=2$ ). The novice instructor T2 made a summary for IF 3, which resulted in 16 indicators (Social Congruence $=10$, Cognitive Congruence $=5$, Content Expertise = 1). Each instructor utilized strategies related to social congruence, cognitive congruence, and content expertise differently. For instructor T1, the utilization of strategies related to social congruence was less than the sum of cognitive congruence and content expertise. In contrast, instructor T2 primarily relied on social congruence strategies and used this strategy more frequently than the sum of cognitive congruence and content expertise strategies. That is, instructor T2 maintained the same facilitation style in the discussions and summary. 
Expert and Novice Facilitation in Online Discussions

Table 2

Frequency of Top 10 Facilitation Strategies used by Both Instructors in Discussion Posts

\begin{tabular}{|c|c|c|c|c|c|}
\hline \multicolumn{3}{|c|}{ Expert Instructor } & \multicolumn{3}{|c|}{ Novice Instructor } \\
\hline Facilitation Strategies & Category & Freq. & Facilitation Strategies & Category & Freq. \\
\hline $\begin{array}{l}\text { 1. Acknowledging student } \\
\text { ideas }\end{array}$ & $\begin{array}{l}\text { Social } \\
\text { Congruence }\end{array}$ & 43 & $\begin{array}{l}\text { 1. Acknowledging student } \\
\text { ideas }\end{array}$ & $\begin{array}{l}\text { Social } \\
\text { Congruence }\end{array}$ & 40 \\
\hline $\begin{array}{l}\text { 2. Addressing student posts } \\
\text { by mentioning their } \\
\text { name(s) }\end{array}$ & $\begin{array}{l}\text { Social } \\
\text { Congruence }\end{array}$ & 25 & $\begin{array}{l}\text { 2. Showing enthusiasm } \\
\text { about student discussion } \\
\text { posts }\end{array}$ & $\begin{array}{l}\text { Social } \\
\text { Congruence }\end{array}$ & 33 \\
\hline $\begin{array}{l}\text { 3. Showing enthusiasm } \\
\text { about student discussion } \\
\text { posts }\end{array}$ & $\begin{array}{l}\text { Social } \\
\text { Congruence }\end{array}$ & 20 & $\begin{array}{l}\text { 3. Addressing student posts } \\
\text { by mentioning their } \\
\text { name }(\mathrm{s})\end{array}$ & $\begin{array}{l}\text { Social } \\
\text { Congruence }\end{array}$ & 24 \\
\hline 4. Connecting content ideas & $\begin{array}{l}\text { Content } \\
\text { Expertise }\end{array}$ & 18 & $\begin{array}{l}\text { 4. Emphasizing and } \\
\text { stressing important ideas }\end{array}$ & $\begin{array}{l}\text { Cognitive } \\
\text { Congruence }\end{array}$ & 15 \\
\hline $\begin{array}{l}\text { 5. Emphasizing and } \\
\text { stressing important ideas }\end{array}$ & $\begin{array}{l}\text { Cognitive } \\
\text { Congruence }\end{array}$ & 17 & $\begin{array}{l}\text { 5. Directing student } \\
\text { attention }\end{array}$ & $\begin{array}{l}\text { Cognitive } \\
\text { Congruence }\end{array}$ & 14 \\
\hline $\begin{array}{l}\text { 6. Directing student } \\
\text { attention }\end{array}$ & $\begin{array}{l}\text { Cognitive } \\
\text { Congruence }\end{array}$ & 17 & $\begin{array}{l}\text { Using direct questions } \\
\text { after reviewing student } \\
\text { responses }\end{array}$ & Content Expertise & 14 \\
\hline 7. Clarifying ideas & $\begin{array}{l}\text { Cognitive } \\
\text { Congruence }\end{array}$ & 12 & 7. Clarifying ideas & $\begin{array}{l}\text { Cognitive } \\
\text { Congruence }\end{array}$ & 11 \\
\hline $\begin{array}{l}\text { 8. Using direct questions } \\
\text { after reviewing student } \\
\text { responses }\end{array}$ & $\begin{array}{l}\text { Content } \\
\text { Expertise }\end{array}$ & 11 & 8. Encouraging students & $\begin{array}{l}\text { Social } \\
\text { Congruence }\end{array}$ & 9 \\
\hline $\begin{array}{l}\text { 9. Referring to the group as } \\
\text { "we", "us", or "our" }\end{array}$ & $\begin{array}{l}\text { Social } \\
\text { Congruence }\end{array}$ & 10 & 9. Greeting students & $\begin{array}{l}\text { Social } \\
\text { Congruence }\end{array}$ & 8 \\
\hline $\begin{array}{l}\text { 10. Inviting students to join } \\
\text { and contribute to the } \\
\text { discussion }\end{array}$ & $\begin{array}{l}\text { Social } \\
\text { Congruence }\end{array}$ & 10 & $\begin{array}{l}\text { 10. Using emotions to } \\
\text { indicate feelings. }\end{array}$ & $\begin{array}{l}\text { Social } \\
\text { Congruence }\end{array}$ & 7 \\
\hline
\end{tabular}


Table 3

Examples of Typical Posts Made by Both Instructors

\begin{tabular}{ll}
\hline Instructor & Example Post with Associated Codes \\
\hline T1 & $\begin{array}{l}\text { Amy (SC-Using a student's name), you really nicely capture the various stakeholder } \\
\text { perspectives here (SC-Acknowledging a student's idea)! Whether sharing the draft document } \\
\text { with Craig was ethical or not, Stan already shared with Craig. So, he does have access to this } \\
\text { information (CC-Clarifying a student's misunderstanding). Now, the question is, should he } \\
\text { use this and if so, how? Let's think about Stan (and the engineers) a little more - what is their } \\
\text { role in this case? Who do they represent (CC-Direct student attention to an important idea)? } \\
\text { While Stan seems pretty intent on sharing his opinions for shaping the training, should he have } \\
\text { that much said? I'm not saying he should or shouldn't - I just think it is something to consider } \\
\text { (E-Tempering instructor expertise)! } \\
\text { This was a powerful and passionate argument, Katie (SC-Using a student's name)! I think } \\
\text { you've done a good job representing the blowback that Michael will get from some critics, if he } \\
\text { chooses to implement in advanced classes SC-Acknowledging a student's idea). I wonder } \\
\text { if/how Michael could reconcile himself to this type of criticism - should he be forced to } \\
\text { implement in advanced classes, etc. (E-Direct questioning of student response). It is } \\
\text { emotionally difficult to hear criticisms of 'elitism' (CC-Direct student attention to an } \\
\text { important idea)! }\end{array}$ \\
\hline
\end{tabular}

Note. SC: social congruence; CC: cognitive congruence; E: content expertise 


\section{Using Facilitation Strategies to Understand Interaction Patterns}

Both instructors facilitated the discussions without making the experience entirely instructor-driven; however, students' activeness in the discussions varied because of the difference in instructor facilitation. As Figure 1 shows, students tended to interact more closely with the expert instructor T1 and maintained relatively sparse interactions with instructor T2. The differences in facilitation methods that both instructors used might aid the understanding of the different interaction patterns.

How and when each instructor used the facilitation methods was noticeably different. Instructor T1 implemented a combination of the strategies more frequently in IF1, suggesting that she established her instructor role at the beginning of the discussion and modeled how to interact with others for instructor T2. That is, instructor T1 used strategies to stretch students' learning to expand the depth of their understanding. While instructor T2 also used a combination of strategies in IF1, she was not as visible as instructor T1, suggesting that she failed to build her instructor role as someone to interact with. In the following discussions, both instructors continued facilitating with various combinations of strategies, and instructor T2 gradually created closer connections with students in IF2 and IF3 (see Figure 1). Table 4 shows the frequency of strategy combinations for each instructor.

Table 4

Frequency of a Combination of Strategies in Each Discussion

\begin{tabular}{llllllllll}
\hline Instructor & IF1 & \multicolumn{9}{c}{ IF2 } & \multicolumn{3}{c}{ IF3 } \\
\hline & $\mathbf{S C}+\mathbf{C C}$ & $\mathbf{S C}+\mathbf{E}$ & $\mathbf{S C}+\mathbf{C C}+\mathbf{E}$ & $\mathbf{S C}+\mathbf{C C}$ & $\mathbf{S C}+\mathbf{E}$ & $\mathbf{S C}+\mathbf{C C}+\mathbf{E}$ & $\mathbf{S C}+\mathbf{C C}$ & $\mathbf{S C}+\mathbf{E}$ & $\mathbf{S C}+\mathbf{C C}+\mathbf{E}$ \\
$\mathrm{T} 1$ & 4 & 3 & 9 & 1 & 6 & 0 & 2 & 2 & 2 \\
$\mathrm{~T} 2$ & 3 & 2 & 4 & 2 & 0 & 4 & 4 & 4 & 4 \\
\hline
\end{tabular}

Note. SC+CC: a combination of social and cognitive congruence; $\mathrm{SC}+\mathrm{E}$ : a combination of social congruence and content expertise; $\mathrm{SC}+\mathrm{CC}+\mathrm{E}$ : a combination of social congruence, cognitive congruence, and content expertise.

\section{Discussion}

In CBL, students are expected to "use old experiences to understand and solve new problems" (Kolodner, 1992, p. 3); however, the application of previous experiences can be challenging (Law et al., 2020). Online case discussions provide opportunities to support students' problemsolving processes (Ertmer \& Koehler, 2014, 2015) and use their previous experiences and knowledge to a great extent. From these discussions, students may gain a more complete understanding of case situations and possible solutions. However, these benefits emerge from productive discussions, and instructors play an active role in engaging students and using various strategies to facilitate online discussions (Ertmer \& Koehler, 2014, 2015). Moreover, as suggested by Doran et al. (2011), intensive instructor involvement may discourage students from responding to one another. We tracked both instructors' centrality measures for the three discussions with varying degrees of involvement to evaluate if students' interactions changed due to instructors' various facilitation levels. The results suggest that when they took a step back in facilitation, the overall student interaction increased, as evident in IF2 and IF3. This is also in line with Rovai's (2007) finding that instructors should avoid being the center of the discussions if they want to see more interaction among students.

Furthermore, our results demonstrated that both instructors used a combination of strategies related to social congruence, cognitive congruence, and content expertise to facilitate the case discussions (Watson et al., 2018), and these three types of facilitation strategies are 
interrelated (Chng et al., 2011). However, when we took a closer look at the facilitation strategies that both instructors used in discussions and summaries, the results showed that the expert instructor T1 was adaptive to meet students' changing needs, while the novice instructor T2 simply used the same strategies when facilitating discussions and bringing closure to the discussion (see Table 5). For example, instructor T1 used a positive tone to express instructor expertise to engage students to think deeply in the discussions and used discussion summaries to help students see connections and emphasize key points that students overlooked in the discussions. This approach is similar to what others have reported. According to Watson et al. (2018), expert facilitators have the skills to adjust their facilitation based on what the students need. Berliner (2001) also emphasized that experts are more flexible than novices. On the other hand, the novice instructor T2 intended to establish an informal relationship with the students and encourage them to interact more in the discussions, but her limited variability in combination with social congruence, cognitive congruence, and content expertise restricted the interactions she was able to facilitate with students.

Table 5

Examples of Discussion Posts and Summaries Made by Both Instructors

\begin{tabular}{|c|c|}
\hline Instructor & Example Posts in Discussions and Summaries \\
\hline \multirow[t]{2}{*}{$\mathrm{T} 1$} & $\begin{array}{l}\text { Cathy, you've shared some great points! I want everyone to think about this some more: "in } \\
\text { order to make everyone happy (which I think is very hard), Craig may need to first prioritize } \\
\text { which stakeholders are being impacted by the training the most." Making everyone happy does } \\
\text { seem like a pretty challenging task, but hopefully Craig can do that-at least make everyone a } \\
\text { little happy! Thinking of this, is there anyone that Craig has to ultimately make happy? In other } \\
\text { words, who is the boss? While Electron is the organization he is working within, who hired } \\
\text { Craig? What do you all think? [IF1 discussion post] }\end{array}$ \\
\hline & $\begin{array}{l}\text { Speaking of the funding agency, this brings up another point worth discussing - stakeholder } \\
\text { roles. While I realize you're still getting the hang of labeling the various individuals involved } \\
\text { with a project, a good rule of thumb is to think of the client as the one providing the funding- } \\
\text { after all these individuals are providing financial means to make the project happen, want to see } \\
\text { a return on their investment, and therefore, get to direct many aspects of the project. [IF2 } \\
\text { discussion summary] }\end{array}$ \\
\hline \multirow[t]{2}{*}{$\mathrm{T} 2$} & $\begin{array}{l}\text { Given everything you know about the case: what's the general ADDIE task (or border between } \\
\text { two ADDIE tasks, in some cases...) that you believe the researcher needs to prioritize RIGHT } \\
\text { NOW-that is, as of the close of the case-to move forward? (This is how (my instructor) } \\
\text { explained to me over time; I struggled with the concept as well! [IF1 discussion post] }\end{array}$ \\
\hline & $\begin{array}{l}\text { I remember being frustrated by the idea of building this kiosk that apparently had to do } \\
\text { everything for everyone and contain such a bewildering range of content (in my mind). My } \\
\text { unhelpful suggestion was that there likely shouldn't be a kiosk at all, unless MAYBE it had a } \\
\text { game on it-and that Lynn should just TAKE OVER THE DESIGN OF THE WHOLE } \\
\text { EXHIBIT (from Laura... somehow?), making sure all relevant wetlands information was in the } \\
\text { exhibit! [IF3 discussion summary] }\end{array}$ \\
\hline
\end{tabular}

Instructor T2 maintained her facilitation efforts by showing understanding towards students' struggles, but she did not consistently use the discussion as a way to emphasize key ideas mentioned by students, cover missed points, or prompt deeper collaborative consideration of case details. Moreover, instructor T1 commonly used questioning to invite students to join and contribute to the discussion, a strategy less commonly used by the novice facilitator. As 
questions during problem-centered experience can greatly influence the learning process (e.g., knowledge construction, interaction [Tawfik et al., 2020]), potentially instructor T1's use of this strategy resulted in differences in network structures. These facilitation differences may help explain why instructor T2 maintained sparse connections with the students across the discussions. Another explanation for instructor T2's sparse connections with students could be the role she established at the beginning of the discussion. While instructor T1 built her instructor role successfully and modeled her facilitation process for instructor T2 in IF1, instructor T2 failed to make students fully aware of her facilitator role. Moreover, instructor T2 was more cognitive congruent across the discussions. This aligns with findings that student facilitators represent more cognitive congruence strategies because they better understand the challenges that are encountered by other students (Dolmans et al., 2002; Schmidt et al., 1994). Perhaps as a first-time instructor of the course, instructor T2 identified more with the student role instead of as a facilitator. If students considered instructor T2 as their peer, they would likely hold back from interacting with her because some students might tend to devalue her facilitation and be reluctant to trust her suggestions (Koehler et al., 2020).

As Figure 1 shows, instructor T2 started to interact with students more closely in IF2 and IF3 than IF1. One potential explanation is that she was better prepared after observing instructor T1's facilitation methods, supporting her to become more comfortable with responding to students' posts when facilitating the discussion. This finding aligns with a meta-analysis indicating that instructors' facilitation abilities were more influential in prompting student learning than content expertise (Leary et al., 2013). Content experts are more directive in problem-centered discussions by correcting students' misconceptions and providing appropriate content-related questions (Schmidt \& Moust, 2000); however, facilitation skills can compensate for novice instructors with limited professional expertise. Thus, it is important to develop facilitation skills and avoid being strong only in one area. According to Richardson and Alsup (2015), novices can learn from expert facilitators to sharpen their facilitation skills in online discussions. Also, expert facilitators can model their facilitation process at the beginning of case discussions to scaffold novice instructors.

Another interesting finding of this study relates to how students gradually took the role of the facilitator in IF2 and IF3. Given the general understanding that instructors are not the authoritative source of information and knowledge in CBL, the instructors took a step back in facilitation after they helped the students become familiar and comfortable with case discussions, and this change motivated and left room for students to embrace the facilitator role. Similarly, Hmelo-Silver (2004) suggested that facilitators diminish their scaffolding gradually as students become more experienced with problem-centered learning to encourage students to take the facilitator role. Moreover, Figure 1 from the SNA emphasizes the importance of purposely finding peripheral or marginal students to encourage them to interact more in the discussions. Although instructor T1 maintained interaction with diverse students, most of the students she interacted with were active students in the discussions. One explanation of this approach is that she intuitively targeted students she sensed she could generate the most interaction from. However, linking less engaged students with active students can possibly prompt all students to take ownership in their learning experience.

\section{Limitations and Future Research}

All participating students were graduate-level students in an online instructional design course. Whether these findings are applicable and generalizable to other levels (e.g., 
undergraduate) and content areas is unclear. Future research is needed to compare these findings with different levels of students across diverse fields. Second, the relationship between students' attributes (e.g., prior knowledge, previous experience, and motivation) and online case-based discussion participation was not examined. Future research should explore the relationship between student attributes, participation, and interaction in asynchronous case discussions. Third, the quality of student posts in response to the instructors' questions was not explored. Instead, we focused on quantifying the dynamics of students' interaction based on the expert and novice instructors' facilitation. Future research is needed to incorporate student perspectives of instructor facilitation and student discussion artifacts to better understand the comparison between expert and novice facilitators. Finally, future studies are needed to triangulate students' social network capacity in discussions and academic performance to consider students' learning behavior and attitudes.

\section{Implications and Conclusion}

Instructors are responsible for keeping discussions focused on key issues and moving the discussion forward productively while avoiding creating a question-answer forum that prevents students' reaching a deeper level (Hew \& Cheung, 2010). Given the complexity and ambiguity of case problems, while not surprising, a novice instructor faces challenges managing discussions. Being a content expert is not a decisive factor in determining if a discussion is effective; instead, facilitation abilities are more critical (Leary et al., 2013). Therefore, novice instructors can seek advice and support from expert instructors prior to facilitating discussions. Additionally, novice and expert instructors can share experiences and discuss improvements for stimulating discussions.

Moreover, instructors' ability to use the combination of adaptive and flexible social congruence, cognitive congruence, and content expertise is significant in engaging students in case discussions. While a more socially congruent facilitator can create a less-threatening environment making students feel comfortable raising their questions and perspectives (Chng et al., 2011), simply using a majority of social congruence strategies does not prompt students to think deeply. Therefore, novice instructors should intentionally identify students' learning gaps and use strategies to help bridge the gaps.

Finally, instructors need to purposely diversify interaction among students with different interaction levels in discussions. If an LMS (e.g., Brightspace) could integrate SNA techniques to identify disconnected students and get a quick snapshot of group interaction characteristics, then it would be helpful for instructors to monitor students' participation and interaction processes. SNA tools (i.e., visualization and metrics) built into an LMS can help instructors visualize their students' interaction and plan interventions accordingly without extracting data from an LMS and importing it to SNA software. This could help lower barriers to entry so that instructors do not need to spend extra time learning how to use SNA tools.

This research offers insight into the difference between how an expert and novice instructor interact with students during case discussions. While distinct differences exist, additional research is needed to fully explore these differences in order to better understand how to best prepare case facilitators to orchestrate maximum outcomes from a case discussion. 


\section{Declarations}

The authors have no relevant financial and non-financial interests to disclose.

Human subject concerns were addressed through approval from the Institutional Review Board (IRB) of Purdue University, USA.

No funding was received to assist with the preparation of this manuscript. 


\section{References}

Andersen, E., \& Schiano, B. (2014). Teaching with cases: A practical guide. Harvard Business Press.

Bastian, M., Heymann, S., \& Jacomy, M. (2009). Gephi: An open source software for exploring and manipulating networks (Version 0.9.2) [Computer software]. International AAAI Conference on Weblogs and Social Media. https://gephi.org/

Berliner, D. C. (2001). Learning about and learning from expert teachers. International Journal of Educational Research, 35(5), 463-482. https://doi.org/10.1016/S0883-0355(02)00004-6

Breiger, R. L. (2004). The analysis of social networks. In M. Hardy, \& A. Bryman (Eds.), Handbook of data analysis (pp. 505-526). Sage.

Carolan, B. (2014). Social network analysis and education theory, methods \& applications. Sage.

Cela, K. L., Sicilia, M. A., \& Sanchez, S. (2015). Social network analysis in e-learning environments: A preliminary systematic review. Educational Psychology Review, 27, 219-246. https://doi.org/10.1007/s10648-014-9276-0

Chng, E., Yew, E. H. J., \& Schmidt, H. G. (2011). Effects of tutor-related behaviours on the process of problem-based learning. Advances in Health Science Education, 16(4), 491-503. http://dx.doi.org/10.1007/s10459-011-9282-7

Creswell, J. W. (2014). A concise introduction to mixed methods research. Sage.

Dolmans, D. H. J. M., Gijselaers, W. H., Moust, J. H. C., Grave, W. S. D., Wolfhagen, I. H. A. P., \& van der Vleuten, C. P. M. (2002). Trends in research on the tutor in problem-based learning: Conclusions and implications for educational practice and research. Medical Teacher, 24(2), 173-180. https://doi.org/10.1080/01421590220125277

Doran, P. R., Doran, C., \& Mazur, A. (2011). Social network analysis as a method for analyzing interaction in collaborative online learning environments. Systemics, Cybernetics and Informatics, 9(7), 10-16.

De Laat, M., Lally, V., Lipponen, L., \& Simons, R. (2007). Investigating patterns of interaction in a networked learning and computer-supported collaborative learning: A role for social network analysis. Computer-Supported Collaborative Learning, 2(1), 87-103. https://doi.org/10.1007/s11412-007-9006-4

Erlin, B., Yusof. N., \& Rahman, A. A. (2009). Analyzing online asynchronous discussion using content and social network analysis. ISDA 2009-Ninth International Conference on Intelligent Systems Design and Applications, 872-877. https://doi.org/10.1109/ISDA.2009.40 
Ertmer, P. A., \& Koehler, A. A. (2014). Online case-based discussions: Examining coverage of the afforded problem space. Educational Technology Research and Development, 62(5), 617636. https://doi.org/10.1007/s11423-014-9350-9

Ertmer, P. A., \& Koehler, A. A. (2015). Facilitated versus non-facilitated online case discussions: Comparing differences in problem space coverage. Journal of Computing in Higher Education, 27(2), 69-93. http://dx.doi.org/10.1007/s12528-015-9094-5

Ertmer, P. A., \& Koehler, A. A. (2018). Facilitating strategies and problem space coverage: Comparing face-to-face and online case-based discussions. Educational Technology Research and Development, 66(3), 639-670. https://doi.org/10.1007/s11423-017-9563-9

Ertmer, P. A., Quinn, J. A., \& Glazewski, K. D. (2017). The ID casebook: Case studies in instructional design. Routledge.

Ertmer, P. A., \& Stepich, D. A. (2002). Initiating and maintaining meaningful case discussions: Maximizing the potential of case-based instruction. Journal of Excellence in College Teaching, $13(2 / 3), 5-18$.

Ertmer, P. A., \& Stepich, D. A. (2005). Instructional design expertise: How will we know it when we see it? Educational Technology, 45(6), 38-43.

Froehlich D. E., Waes, S. V., \& Schafer, H. (2020). Linking quantitative and qualitative network approaches: A review of mixed methods social network analysis in education research. Review of Research in Education, 44, 244-268. https://doi.org/10.3102\%2F0091732X20903311

Goeze, A., Zottmann, J. M., Vogel, F., Fischer, F., \& Schrader, J. (2014). Getting immersed in teacher and student perspectives: Facilitating analytical competence using video cases in teacher education. Instructional Science, 42(1), 91-114. https://doi.org/10.1007/s11251-013-9304-3

Hara, N., Bonk, C. J., \& Angeli, C. (2000). Content analysis of online discussion in an applied educational psychology course. Instructional Science, 28(2), 115-152.

Hew, K. F., \& Cheung, W. S. (2010). Fostering higher knowledge construction levels in online discussion forums: An exploratory case study. International Journal of Web-Based Learning and Teaching Technologies, 5(4), 44-55.

Hmelo-Silver, C. E. (2004). Problem-based learning: What and how do students learn? Educational Psychology Review, 16(3), 235-266.

Hmelo-Silver, C. E., \& Barrows, H. S. (2006). Goals and strategies of a problem-based learning facilitator. Interdisciplinary Journal of Problem-Based Learning, 1(1), 21-39.

https://doi.org/10.7771/1541-5015.1004 
Hoey, R. (2017). Examining the characteristics and content of instructor discussion interaction upon student outcomes in an online course. Online Learning, 21(4), 263-281.

https://doi.org/10.24059/olj.v21i4.1075

Johnson, R. B., Onwuegbuzie, A. J., \& Turner, L. A. (2007). Towards a definition of mixed methods research. Journal of Mixed Methods Research, 1(2), 112-133.

https://doi.org/10.1177\%2F1558689806298224

Jonassen, D. H. (2011). Supporting problem solving in PBL. Interdisciplinary Journal of

Problem Based Learning, 5(2), 95-112. https://doi.org/10.7771/1541-5015.1256

Kassab, S., Al-Shboul, Q., Abu-Hijleh, M., \& Hamdy, H. (2006). Teaching styles of tutors in a problem-based curriculum: Students' and tutors' perception. Medical Teacher, 28(5), 460-464. https://doi.org/10.1080/01421590600627540

Koehler, A. A., Cheng, Z., Fiock, H., Janakiraman, S., \& Wang, H. (2020). Asynchronous online discussions during case-based learning: A problem-solving process. Online Learning, 24(4), 6492. https://doi.org/10.24059/olj.v24i4.2332

Koehler, A. A., Ertmer, P. A., \& Newby, T. J. (2019). Developing preservice teachers' instructional design skills through case-based instruction: Examining the impact of discussion format. Journal of Teacher Education, 70(4), 319-334.

https://doi.org/10.1177\%2F0022487118755701

Kolodner, J. L. (1992). An introduction to case-based reasoning. Artificial Intelligence Review, 6, 3-34.

Law, V., Ge, X., \& Huang, K. (2020). Understanding learners' challenges and scaffolding their ill-structured problem solving in a technology-supported self-regulated learning environment. In M. J. Bishop, E. Boling, J. Elen \& V. Svihla (Eds.), Handbook of Research in Educational Communications and Technology (pp. 321-342). Springer, Cham. https://doi.org/10.1007/978-3030-36119-8_14\#DOI

Leary, H., Walker, A., Shelton, B. E., \& Fitt, M. H. (2013). Exploring the relationships between tutor background, tutor training, and student learning: A problem-based learning meta-analysis. Interdisciplinary Journal of Problem Based Learning, 7(1), 41-66. https://doi.org/10.7771/1541$\underline{5015.1331}$

Richardson, J. C., \& Alsup, J. (2015). From the classroom to the keyboard: How seven teachers created their online teacher identities. The International Review of Research in Open and Distributed Learning, 16(1), 142-167.

Richardson, J. C., Koehler, A. A., Besser, E. D., Caskurlu, S., Lim, J., \& Muller, C. M. (2015). Conceptualizing and investigating instructor presence in online learning environment. International Review of Research in Open and Distributed Learning, 16(3), 256-297. http://dx.doi.org/10.19173/irrodl.v16i3.2123 
Rico, R., \& Ertmer, P. A. (2015). Examining the role of the instructor in problem-centered instruction. TechTrends, 59(4), 96-103.

Rovai, A. P. (2007). Facilitating online discussions effectively. The Internet and Higher Education, 10(1), 77-88. https://doi.org/10.1016/j.iheduc.2006.10.001

Schmidt, H. G. (1994). Resolving inconsistencies in tutor expertise research: Does lack of structure cause students to seek tutor guidance? Academic Medicine, 69(8), 656-662.

Schmidt, H. G., \& Moust, J. H. (1995). What makes a tutor effective? A structural-equation modeling approach to learning in problem-based curricula. Academic Medicine, 70(8), 708-714. https://doi.org/10.1097/00001888-199508000-00015

Schmidt, H. G., \& Moust, J. H. (2000). Factors affecting small-group tutorial learning: A review of research. In D. H. Evensen \& C. E. Hmelo-Silver (Eds.), Problem-based learning: A research perspective on learning interactions (pp. 19-52). Erlbaum.

Schmidt H. G., Van der Arend, A., Koxx, I., \& Boon, L. (1994). Peer versus staff tutoring in problem-based learning. Instructional Science, 22(4), 279-285.

Schmidt, H. G., Van der Arend, A., Moust, J. H., Koxx, I., \& Boon, L. (1993). Influence of tutors' subject-matter expertise on student effort and achievement in problem-based learning. Academic Medicine, 68(10), 784-791. https://doi.org/10.1007/bf00891781

Tawfik, A., Graesser, A., Gatewood, J., \& Gishbaugher, J. (2020). Role of questions in inquirybased instruction: Towards a design taxonomy for question-asking and implications for design. Educational Technology Research and Development, 68(2), 653-678. https://doi.org/10.1007/s11423-020-09738-9

Tawfik, A., \& Jonassen, D. (2013). The effects of successful versus failure-based cases on argumentation while solving decision-making problems. Educational Technology Research and Development, 61(3), 385-406.

Watson, S. L., Koehler, A. A., Ertmer, P. A., Kim, W., \& Rico, R. (2018). An expert instructor's use of social congruence, cognitive congruence, and expertise in an online case-based instructional design course. Interdisciplinary Journal of Problem-Based Learning, 12(1). https://doi.org/10.7771/1541-5015.1633

Yang, S., Keller, F., \& Zheng, L. (2017). Social network analysis: Method and examples. Sage.

Yew, E. H. J., \& Schmidt, H. G. (2012). What students learn in problem-based learning: A process analysis. Instructional Science, 40, 371-395.

Yew, E. H. J., \& Yong, J. J. Y. (2014). Student perceptions of facilitators' social congruence, use of expertise, and cognitive congruence in problem-based learning. Instructional Science, 42, $795-815$. 


\section{Appendix A}

Codebook and Frequencies

\begin{tabular}{|c|c|c|c|c|c|c|c|}
\hline Instructor & Categories & IF1 & IF2 & IF3 & $\begin{array}{l}\text { IF1 } \\
\text { Summary }\end{array}$ & $\begin{array}{l}\text { IF2 } \\
\text { Summary }\end{array}$ & $\begin{array}{l}\text { Total } \\
\text { Counts by } \\
\text { Indicator }\end{array}$ \\
\hline \multirow{29}{*}{$\mathrm{T} 1$} & Social Congruence & & & & & & \\
\hline & Af-Value & & & & & & \\
\hline & Af-Emotion & 1 & & 1 & & & 2 \\
\hline & Af-Enthusiasm & 12 & 2 & 4 & 1 & 1 & 20 \\
\hline & Af-Humor & 2 & & & & & 2 \\
\hline & Af-RichMedia & & & & & & \\
\hline & Co-Greeting \& Salutations & 3 & 2 & & 2 & 1 & 8 \\
\hline & Co-Name & 11 & 7 & 7 & & & 25 \\
\hline & Co-Encourage & & & & 1 & 1 & 2 \\
\hline & Co-Group Reference & 4 & 1 & & 3 & 2 & 10 \\
\hline & Co-Collaborative & & & & & & \\
\hline & Co-Diversity & & & & & & \\
\hline & Ak-Acknowledgment & 24 & 8 & 4 & 5 & 2 & 43 \\
\hline & AG-Agreement/Disagreement & & & 1 & & & 1 \\
\hline & AP-Approval & 3 & & & & & 3 \\
\hline & I-Invitation & 3 & 4 & 3 & & & 10 \\
\hline & Total Social Indicators & 63 & 26 & 20 & 13 & 7 & 129 \\
\hline & Cognitive Congruence & & & & & & \\
\hline & FD-Emphasis & 1 & & & 7 & 9 & 17 \\
\hline & FD-DirectStudentAttention & 7 & 1 & 3 & 5 & 1 & 17 \\
\hline & FD-Tips & 3 & & & & & 3 \\
\hline & FD-Summary & 2 & & 2 & & 1 & 5 \\
\hline & FD-TipsOutside & & & & & & \\
\hline & DI-Clarify & 5 & 1 & 2 & 2 & 2 & 12 \\
\hline & DI-Example & 2 & & & & & 2 \\
\hline & DI-Demo & & & & & & \\
\hline & DI-Resource & & & & & 1 & 1 \\
\hline & Total Cognitive Indicators & 20 & 2 & 7 & 14 & 14 & 57 \\
\hline & Content Expertise & & & & & & \\
\hline
\end{tabular}




\begin{tabular}{|c|c|c|c|c|c|c|c|}
\hline & FD-Prompt & 2 & 2 & 2 & & & 6 \\
\hline & FD-AskforClarification & & 1 & & & & 1 \\
\hline & FD-ConnectsContentIdeas & 6 & 4 & 2 & 4 & 2 & 18 \\
\hline & FD-AltViewPoint & & & & & & \\
\hline & DI-DirectQuestion & 6 & 3 & 2 & & & 11 \\
\hline & As-FromDiscussion & & & 1 & & & 1 \\
\hline & TemperingExpertise & 7 & & & & & 7 \\
\hline & Total Expertise Indicators & 21 & 10 & 7 & 4 & 2 & 44 \\
\hline \multirow{25}{*}{$\mathrm{T} 2$} & Categories & IF1 & $\mathrm{IF} 2$ & IF3 & \multicolumn{2}{|l|}{ IF3 Summary } & $\begin{array}{l}\text { Total } \\
\text { Counts by } \\
\text { Indicator }\end{array}$ \\
\hline & Social Congruence & & & & & & \\
\hline & Af-Self Disclosure & 2 & 1 & 1 & \multicolumn{2}{|l|}{1} & 5 \\
\hline & Af-Value & & & & & & \\
\hline & Af-Emotion & 4 & & 3 & & & 7 \\
\hline & Af-Enthusiasm & 6 & 11 & 14 & \multicolumn{2}{|l|}{2} & 33 \\
\hline & Af-Humor & 1 & & & & & 1 \\
\hline & Af-RichMedia & & & & & & \\
\hline & Co-Greeting \& Salutations & 6 & 2 & & & & 8 \\
\hline & Co-Name & 4 & 6 & 13 & \multicolumn{2}{|l|}{1} & 24 \\
\hline & Co-Encourage & 8 & & & \multicolumn{2}{|l|}{1} & 9 \\
\hline & Co-Group Reference & 3 & 1 & & & 4 \\
\hline & Co-Collaborative & & & & & \\
\hline & Co-Diversity & & & & & \\
\hline & Ak-Acknowledgment & 2 & 14 & 19 & \multicolumn{2}{|l|}{5} & 40 \\
\hline & AG-Agreement/Disagreement & 2 & & & & 2 \\
\hline & AP-Approval & 1 & & & & 1 \\
\hline & I-Invitation & 1 & & 2 & & 3 \\
\hline & Total Social Indicators & 40 & 35 & 52 & & 127 \\
\hline & Cognitive Congruence & & & & & \\
\hline & FD-Emphasis & 4 & 2 & 7 & \multicolumn{2}{|l|}{2} & 15 \\
\hline & FD-DirectStudentAttention & 6 & 5 & 1 & \multicolumn{2}{|l|}{2} & 14 \\
\hline & FD-Tips & 1 & & & & 1 \\
\hline & FD-Summary & & & & \multicolumn{2}{|l|}{1} & 1 \\
\hline & FD-TipsOutside & 1 & & & & 1 \\
\hline
\end{tabular}




\begin{tabular}{|l|l|l|l|l|l|} 
& 5 & & 6 & & 11 \\
\hline DI-Clarify & & & & & 1 \\
\hline DI-Example & & 1 & & & \\
\hline DI-Demo & & & & & \\
\hline DI-Resource & & & & & 44 \\
\hline Total Cognitive Indicators & 17 & 8 & 14 & 5 & \\
\hline Content Expertise & & & & & \\
\hline FD-Prompt & & & & & 2 \\
\hline FD-AskforClarification & & 1 & 1 & & 5 \\
\hline FD-ConnectsContentIdeas & & 1 & 3 & 1 & 1 \\
\hline FD-AltViewPoint & 1 & & & & 4 \\
\hline DI-DirectQuestion & 5 & 3 & 6 & & 1 \\
\hline As-FromDiscussion & 2 & & 2 & & 27 \\
\hline TemperingExpertise & & & 1 & & 14 \\
\hline Total Expertise Indicators & 8 & 5 & 13 & 1 & \\
\hline
\end{tabular}

